\title{
Hydrophobic Interaction Chromatography and Modeling of Protein Adsorption on Hydrophobic Gel
}

\author{
Ahmad Hassan a, Saad Rabbani a , Azwan Morni b , Husam Ali Jafar a, \\ a Department of Chemistry, University of Baghdad, Iraq \\ ${ }^{b}$ Department of Chemical Engineering, University of Putra Malaysia, Malaysia
}

\section{Keywords}

\section{Thermodynamic,}

Adsorption,

Hydrophobic,

Equilibrium,

Interaction,

Chromatography

\begin{abstract}
In this work the thermodynamic model of Chen and Sun which describes the adsorption of protein on a hydrophobic gel in hydrophobic interaction chromatography process is modified by substitution activity instead of protein and salt concentration in liquid phase. The model is based on two-state equilibrium of protein in solution and adsorbed phase. Also, the effect of salt concentration and type of hydrophobic gel on the amount of protein adsorption is investigated. Finally, the accuracy of model is evaluated by measuring average absolute deviation (AAD) for adsorption isotherm in different salt concentration. The results show that the modified model had high accuracy for prediction the adsorption isotherm in different type of adsorbed and salt concentration.
\end{abstract}

\section{Introduction}

Hydrophobic interaction chromatography (HIC) is a powerful method which used in the purification of protein [1-4]. This process is established upon the hydrophobic interaction between hydrophobic ligands and non-polar residues on the surface of proteins. So, it can be used as a powerful adsorptive separation method in purification of biomolecules. In addition, it is commonly technique in comparison with others methods for purification of biomolecules because of the fast separations achieved with little product declination, low solven requirements and very good purification levels. There have been many efforts about understanding of the mechanism of protein retention in hydrophobic chromatography process [1, 13-28]. The solvophobic theory describes adsorption in terms of the molar surface tension increment of the salt. In 1986 Fausnaugh and Rangier investigated the HIC adsorption of proteins in the presence of different types of salts and they find that the solvophobic theory could not completely explain the adsorption differences. In 1988 Timasheff and Arakawa explained specific salt-protein interactions in aqueous solutions in term of Preferential Interaction theory (PIT) [22-25, 28-39]. According to the PIT, lyotropic salts promote protein salting out by being preferentially excluded from the protein surface, by means of that promoting hydration of the surface and enhancing the protein stability. On the other hand, specific interactions of salt with proteins at high salt concentration, increases the protein solubility and also destabilizing the protein. Perkins et al extended the process to HIC of proteins. The Solvophobic theory and PIT are interrelated, because the Solvophobic theory explaining surface tension effects and the PIT explaining salt-protein interactions. Other works which are done about treatments of protein precipitation and HIC include activitycoefficient-based models and those based on molecular thermodynamics or the potential of mean force [40-45]. One of the other method for modeling salt effects in protein adsorption in HIC process was done by Chen and Sun who describes attraction of hydrophobic surfaces on the protein surface and hydrophobic ligands in presence of salt ions but the model didn't show high accuracy for prediction of the protein adsorption isotherm and it was because of Chen and Sun assumption that they assume the liquid phase are thermodynamically ideal and they use concentration instead of activity which made some error [2, 46-59].
In this paper, thermodynamic model of Chen and Sun is modified by substitution activity instead of protein and salt concentration in liquid phases. Further, we compare the results of the modified model with adsorption isotherm of Chen and Sun to evaluation of the accuracy of the model. The processing tube tension-reducing is an important and complex deformation process in the producing seamless tubes, which is influenced by the materials properties, deformation temperature and rolling rate, stress, contact and friction condition, reducing size and others, which are a non-isothermal steady-state coupled with non-steady-state three-dimensional thermo-mechanical process [3, 4, 45, 60-69].

Hydrophobic interaction chromatography (HIC) is one of the most widely used methods for separating and purifying proteins in their native state. HIC also proves to be quite useful in isolating protein complexes and in studying protein folding and unfolding. So, how does HIC work? What are the principles behind this technique? To understand the mechanism behind this type of chromatography, here are some things you definitely need to know.

In a nutshell, HIC (also known as 'salting out') separates protein molecules using the properties of hydrophobicity. In this method, proteins containing both hydrophilic and hydrophobic regions are applied to an HIC column under high salt buffer conditions.

The salt in the buffer (usually ammonium sulfate) reduces the solvation of sample solutes and exposes the hydrophobic regions along the surface of the protein molecule. This facilitates the adsorption of these hydrophobic regions to the hydrophobic areas on the solid support and precipitates (crystallizes) proteins out of the solution.

Keep in mind that when performing this type of chromatography, the addition of lyotropic salts enhances the hydrophobic effect and reduces the number and volume of individual hydrophobic cavities while decreasing the salt concentration will result in desorption from the solid support. As such, sample elution can be facilitated through decreasing salt gradient. Mild organic modifiers or detergents may also be added to the elution buffer to aid in the elution process.

Using the principles of HIC, you can bind proteins from aqueous solutions in varying degrees depending on the structure of your protein of interest, salt concentration, $\mathrm{pH}$, temperature and organic solvents used. 


\section{METHOD OF THERMODYNAMIC MODELING}

\subsection{Principle of the model}

In aqueous solution, hydrophobic surfaces on the protein are covered with an ordered water molecule (Figure 1a). HIC is based on the iii. reversible interaction between a protein surface and chromatographic adsorbents. The proteins are separated according to iv. the differences in the amount of exposed hydrophobic amino acids. To facilitate hydrophobic interactions, the protein mixture is loaded to the column with high salt concentration buffer. In this model we consider a system consist of a hydrophobic resin, hydrophobic ligand, protein and certain salts. According to the model of Chen and Sun, there are two phases in the solution for the protein molecules, which are the hydrated and dehydrated state and only the dehydrated phase can interact with the hydrophobic ligand and hydrated state cannot interact with the hydrophobic ligand, because the water molecules cover the surface of this state of protein. By adding salt molecules, the ability of water molecules for hydration of salt molecules are more than its ability for hydration of protein molecules, so hydrophobic surfaces on the protein molecules can react with the hydrophobic ligands (Figure 1b).

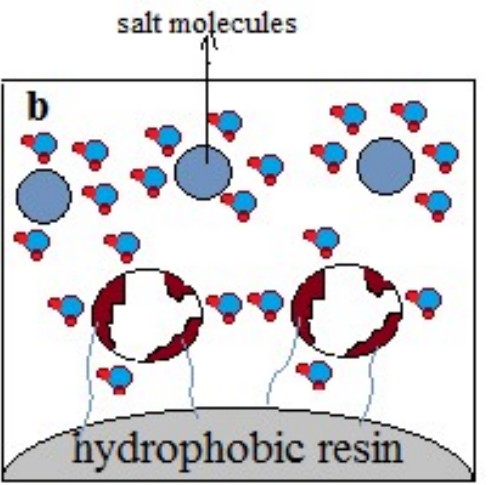

ordered water molecules hydrophobic surfaces

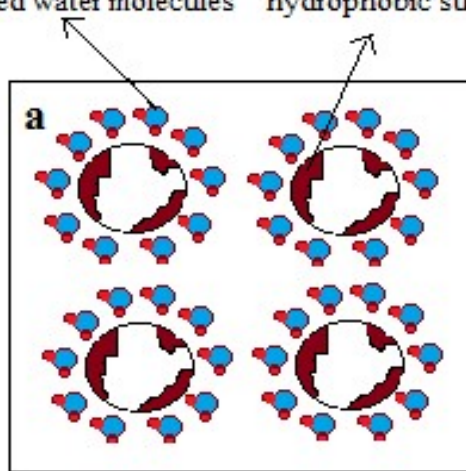

Figure. 1a ordered water molecules which cover the hydrophobic surface of proteins. Figure. $1 \mathrm{~b}$ hydrophobic interaction between hydrophobic resin and hydrophobic surface of protein in presence of salt

For simplification of the model, the following assumptions were considered:

i. The salt cannot affect on the hydrophobic ligand groups. In opposite, the protein hydrophobicity will be improved with increasing the salt concentration. ii.

Solid phases, such as the hydrophobic ligand and adsorbed protein in the substrate phase, are thermodynamically ideal, so we can use the concentration, instead of activity.

Adsorption equilibrium between the hydrophobic ligand and protein is reversible

The ion-exchange effect in the protein adsorption on the hydrophobic substrate is very small, so we can ignore from this effect.

Eq. (1) shows the adsorption isotherm which was predicted by the model of Chen and Sun.

$\frac{\mathrm{Q}}{\mathrm{Cp}}=\frac{\mathrm{KsKpC}_{\mathrm{s}}^{\alpha}[n-(\sigma+n) \mathrm{Q}]^{\mathrm{n}}}{1+\mathrm{KsC}_{\mathrm{s}}^{\alpha}}$

$\mathrm{Q}, \mathrm{Cp}, \wedge, \alpha, \mathrm{CS}$ and $\sigma$ stand for complex concentration, protein concentration, density of ligand, salt coefficient, salt concentration and strict factor, respectively. In addition, $\mathrm{Kp}$ and $\mathrm{Ks}$ stand for the protein adsorption equilibrium constants and protein dehydration equilibrium and $n$ represent the number of ligands that can interact with one protein molecule.

\subsection{Modifying the model}

Modifying of the model of Chen and Sun will be done by substitution activity instead of protein and salt concentration. Eqn. (2) shows the modified equation for prediction of adsorption isotherm.

$\frac{\mathrm{Q}}{\mathrm{Cp}}=\frac{\gamma_{p} \mathrm{KsKp}\left(\gamma_{s} C_{s}\right) \alpha[\mathrm{n}-(\sigma+\mathrm{n}) \mathrm{Q}]^{\mathrm{n}}}{1+\mathrm{Ks}\left(\gamma_{s C_{s}}\right) \alpha}$

In which $\gamma s$ and $\gamma p$ are the activity coefficients of the salt and protein, respectively. For calculation of activity coefficient of protein in solution phase we used the result of Moller up and for calculation of activity coefficient of the salt we used Debye-Huckel equation. So the modified adsorption isotherm equation in presence of ammonium sulfate can be rewritten as Eqn. (3)

$$
Q=\frac{C_{1} \exp \left(Z_{S} C_{S}\right) K_{S} K_{p}\left[\exp \left(\frac{-S \sqrt{3 C_{S}}}{1+A \sqrt{3 C_{S}}}+2 B\left(3 C_{S}\right)+1.5\left(3 C_{S}^{2}\right)+0.75 D\left(3 C_{S}^{2}\right)\right)\right] \alpha[n-(\sigma+n) Q]^{n}}{1+K_{S}\left[\exp \left(\frac{-S \sqrt{3 C_{S}}}{1+A \sqrt{3 C_{S}}}+2 B\left(3 C_{S}\right)+1.5\left(3 C_{S}^{2}\right)+0.75 D\left(3 C_{S}^{3}\right)\right)\right]}
$$

In which ZS is constant which depend on the charge of the protein and thus on $\mathrm{pH}$ [22] and $\mathrm{c} 1$ is a coefficient which are related to the activity coefficient of protein in pure water. Also, A, B, C and D are the empirical constants and do not have physical significance and are determined by measuring the osmotic coefficients.

Table 1. Constants for Debye Huckel Equations

$\begin{array}{ccccc}\text { Salt } & \mathrm{A} & \mathrm{B} \times 10^{2} & \mathrm{C} \times 10^{3} & \mathrm{D} \times 10^{4} \\ \left(\mathrm{NH}_{4}\right)_{2} \mathrm{SO}_{4} & 0.8 & 18.07 & 25.25 & 0.023\end{array}$

\section{RESULTS AND DISCUSSION}

\subsection{Determination of parameters}

The protein and adsorbents, which were used in this modelling, are lysozyme and different type of Sepharose gels (butyl Sepharose, phenyl Sepharose low substitution and phenyl Sepharose high substitution). By using the experimental data for adsorption of a lysozyme in different salt concentration of ammonium sulfate we can calculate the model parameters. This work has been done with genetic algorithm. All of the parameters expect strict factor are determined with the optimization. By the maximum adsorption the strict factor can be calculated. Table (2) Shows the parameters of model for adsorption of lysozyme on different type of Sepharose gels.

Table 2. The Calculated model parameters for adsorption of lysozyme on phenyl Sepharose high sub, phenyl Sepharose low sub and butyl Sepharose in presence of ammonium sulfate

\begin{tabular}{|c|c|c|c|c|c|c|}
\hline Resin & Ks & $K_{p}$ & $n$ & $\alpha$ & $\mathrm{CL}$ & $Z_{s}$ \\
\hline Phenel Sepharose high sub & 0.00039 & $3.8 * 10^{11}$ & 3.815 & 2.04 & 0.928 & 0.93 \\
\hline Phenel Sepharose low sub & 0.00030 & $2.8 * 10^{10}$ & 3.60 & 1.91 & 0.958 & 0.86 \\
\hline Butyl Sepharose & 0.00024 & $1.8 * 10^{9}$ & 3.40 & 1.52 & 0.911 & 0.98 \\
\hline
\end{tabular}

Table 3: Average absolute percentage deviation for adsorption isotherm of lysozyme on different gel in presence of ammonium sulfate 


\begin{tabular}{|c|c|c|c|c|c|c|c|c|c|c|c|c|}
\hline \multirow{2}{*}{$\begin{array}{l}\text { Type of resin } \\
\mathrm{Cs}(\mathrm{mol} / \mathrm{L})\end{array}$} & \multicolumn{4}{|c|}{ Butyl Sepharose } & \multicolumn{4}{|c|}{ Phenyl Sepharose low sub } & \multicolumn{4}{|c|}{ Phenyl Sepharose high sub } \\
\hline & 0.5 & 0.8 & 1.2 & 1.4 & 0.5 & 0.8 & 1.2 & 1.4 & 0.5 & 0.8 & 1.2 & 1.4 \\
\hline
\end{tabular}

\subsection{Adsorption isotherm}

When the parameters are determined, Eqn. (3) can be used for calculation of adsorption isotherm for all type of Sepharose gels. The Figure (2-4) show the adsorption isotherm of lysozyme on butyl Sepharose, phenyl Sepharose low sub, phenyl Sepharose high sub respectively. The experimental and predicted data (which was calculated from this model) are showed in the figures. As the curves showed in all concentration of salt and protein, the model can predict the adsorption isotherm in acceptable level of accuracy.

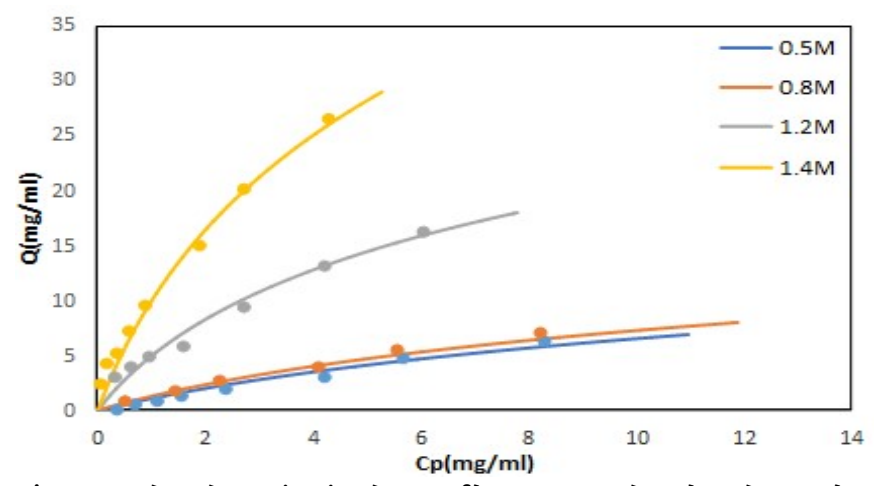

Figure 2. The adsorption isotherm of lysozyme on butyl Sepharose low sub in presence of ammonium sulfate

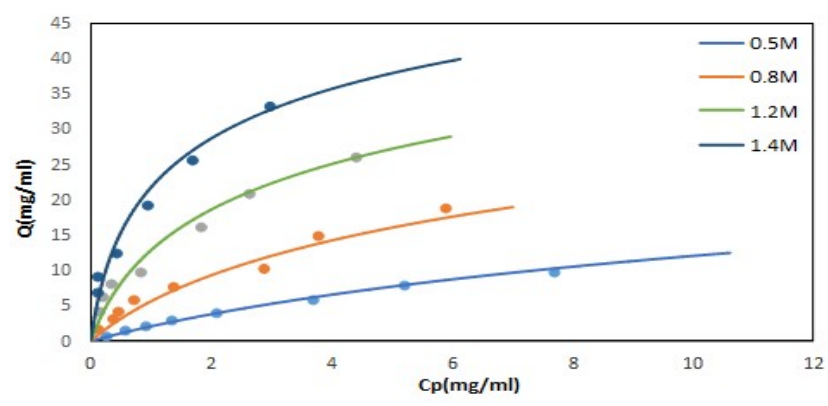

Figure 3. The adsorption isotherm of lysozyme on phenyl Sepharose low sub in presence of ammonium sulfate

\section{Declaration of Conflict of Interests}

The authors declare that there is no conflict of interest.

\section{REFERENCES}

[1.] Mostafavi, S.M., et al. Electrochemical Study and Determination of Thiophene by Cobalt Oxide Nanoparticle Modified Glassy Carbon Electrode. in 6th Aegean Analytical Chemistry Days (AACD), Denizli, Turkey. (2008)

[2.] Bayat, M. and S.M. Mostafavi, Investigation of Interleukin 2 as Signaling Molecule in Human Serum Albumin. The Pharmaceutical and Chemical Journal, (2018). 5(02): p. 183-189.

[3.] Z. Man, A.G.E., S. M. Mostafavi, A. Surendar, Fuel oil characteristics and applications: economic and technological aspects. Petroleum Science and Technology, (2019).

[4.] Eissazadeh, S., et al., Application of Polyaniline Nanostructure Based Biosensor For Glucose And Cholesterol Detection. RESEARCH JOURNAL OF PHARMACEUTICAL BIOLOGICAL AND CHEMICAL SCIENCES, (2019). 10(1): p. 150-157.

[5.] Amiri Koohpayeh, J., A Review on Waste Management of Radioactive Materials and its Economic Effects. Medbiotech Journal, (2020) 04(01): p. 1-7.

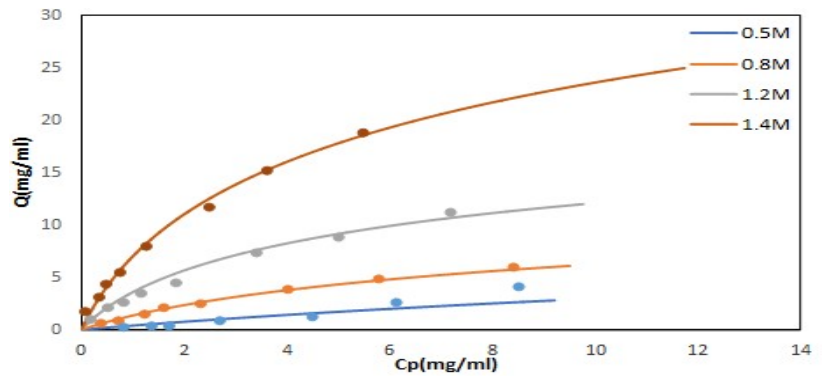

Figure 4. The adsorption isotherm of lysozyme on phenyl Sepharose high sub in presence of ammonium sulfate.

\subsection{ERROR ANALYSIS}

Average absolute deviation (AAD) was calculated for analysis of the model accuracy. Table. (3) Show AAD for adsorption isotherm of lysozyme on three Sepharose gels. The value of AAD for all gels are in appropriate limit, so the accuracy of this model is acceptable accuracy.

\subsection{Comparing the Real samples and the Model}

As it was mentioned in [6], the pattern of changes in the real samples in the presence of other peptides and proteins is different. Because at the digestion process, the sample receive high volume of salt that creates a strong electrolyte. This could produce a media that change the form of peptide in the water and so, the absorbance can be changed [48-49].

\section{CONCLUSION}

As conclusion, the adsorption isotherm of lysozyme on butyl Sepharose, phenyl Sepharose low sub, phenyl Sepharose were increased respectively. The protein and adsorbents, which were utilized in this demonstrating, are lysozyme and diverse kind of Sepharose gels (butyl Sepharose, phenyl Sepharose low replacement and phenyl Sepharose high replacement). By utilizing the trial information for adsorption of a lysozyme in various salt convergence of ammonium sulfate we can ascertain the model parameters. This work has been finished with hereditary calculation. The experimental and predicted data showed that the deviation of absorbance increases by decreasing the concentration of salt in the protein and the model can predict the adsorption isotherm in acceptable level of accuracy.

[6.] Mahmoudi, A., Water and Wastewater Industry and Energy Management. Medbiotech Journal, (2020) 04(01): p. 8-12.

[7.] Sadeghi, L., Cytotoxic Effects of Iron Oxide Nanoparticles on Hep G2 Cells. Medbiotech Journal, 2020. 04(01): p. 13-18.

[8.] Al Maghrebi, O., Sol-Gel Fabrication of Polyimide-Silica Hybrid Film and its Characterization through TGA and FTIR. Medbiotech Journal, (2020) 04(01): p. 27-29.

[9.] Moradmandnia, S. and A. Sarlak, The Study of Manufacturing Methodology of Nanocrystals in Science and Engineering. Medbiotech Journal, (2020) 04(01): p. 22-26.

[10.] Rafieinasab, S. and J. Sedaghatnia, Electrocoating of Titanium Nanoparticle and Investigation of its Characters. Medbiotech Journal, (2020) 04(01): p. 19-21.

[11.] Astaraki, N. and S. Goudarzi, Fabrication of Biocompatible Surface through Fixation of Silver Nanoparticles Assembled on Polyurethane. Medbiotech Journal, (2020) 04(01): p. 30-35.

[12.] Abdollah, H., Sol-Gel Preparation of Pd Nanoparticle over $\gamma$-Al2O3 and its Application in Hydrogenation of Nitrobenzene. Medbiotech Journal, (2020) 04(01): p. 36-39.

[13.] Seyed Mojtaba Mostafavi, S.A., Iman Seyedi, Mohammad Hoseini, Excel for Engineers. (2009), Toranj Group Publication, Ltd.

[14.] Seyed Mojtaba Mostafavi, A.R., Masoumeh Piryaei, Electrochemistry: principles, methods, and applications. Toranj Group Publication, Ltd. (2009) 
[15.] Seyed Mojtaba Mostafavi, A.M., Determination of molecular structure by identification of functional groups. Toranj Group Publication, Ltd., Isfahan, Iran. (2010),

[16.] Seyed Mojtaba Mostafavi, O.Z., Thermodynamics: an engineering approach. Mani Publication, Ltd, Isfahan, Iran (2010)

[17.] Seyed Mojtaba Mostafavi, B.R., Nanomaterial Chemistry. Toranj Group Publication, Ltd. (2010)

[18.] Seyed Mojtaba Mostafavi, A.R., Mina Adibi, Farshid Pashaee, Masoumeh Piryaei, Modification of Glassy Carbon Electrode by a Simple, Inexpensive and Fast Method Using an Ionic Liquid Based on Immidazolium as Working Electrode in Electrochemical Determination of Some Biological Compounds. Asian Journal of Chemistry, (2011) 23(12).

[19.] Seyed Mojtaba Mostafavi, A.R., Mina Adibi, Farshid Pashaee, Masoumeh Piryaei, Electrochemical Investigation of Thiophene on Glassy Carbon Electrode and Quantitative Determination of it in Simulated Oil Solution by Differential Pulse Voltammetry and Amperometry Techniques. Asian Journal of Chemistry, (2011) 23(12): p. 5356-5360.

[20.] MOSTAFAVI, S.M., et al., Modification of Glassy Carbon Electrode by a Simple, Inexpensive and Fast Method Using an Ionic Liquid Based on Immidazolium as Working Electrode in Electrochemical Determination of Some Biological Compounds. Asian Journal of Chemistry, (2011) 23(12).

[21.] S. Mojtaba Mostafavi, A.R., Mina Adibi, Farshid Pashaee And M. Piryaei, Electrochemical Investigation of Thiophene on Glassy Carbon Electrode and Quantitative Determination of it in Simulated Oil Solution by Differential Pulse Voltammetry and Amperometry Techniques. Asian Journal of Chemistry, (2011) 23(12): p. 5356-5360.

[22.] Seyed Mojtaba Mostafavi, A.R., Ali Akbar Miranbeigi, Handbook of Mineral Analysis. Mani Publication, Ltd, Isfahan, Iran. (2012)

[23.] Seyed Mojtaba Mostafavi, M.P., Ahmad Rouhollahi and A. Mohajeri, Separation and Quantification of Hydrocarbons of LPG Using Novel MWCNT-Silica Gel Nanocomposite as Packed Column Adsorbent of Gas Chromatography. Journal of NanoAnalysis, (2014) 1(01): p. 01.

[24.] Seyed Mojtaba Mostafavi, M.P., Ahmad Rouhollahi and A. Mohajeri, Separation of Aromatic and Alcoholic Mixtures using Novel MWCNT-Silica Gel Nanocomposite as an Adsorbent in Gas Chromatography. Journal of NanoAnalysis, (2014) 1(01): p. 11

[25.] Mostafavi, S.M., 3D Graphene Biocatalysts for Development of Enzymatic Biofuel Cells: A Short Review. Journal of Nanoanalysis, (2015) 2(2): p. 57-62.

[26.] Zabihi, O., et al., The effect of zinc oxide nanoparticles on thermophysical properties of diglycidyl ether of bisphenol A/2, 2' Diamino-1, 1'-binaphthalene nanocomposites. Thermochimica acta, (2011) 521(1-2): p. 49-58

[27.] Zabihi, O., A. Khodabandeh, and S.M. Mostafavi, Preparation, optimization and thermal characterization of a novel conductive thermoset nanocomposite containing polythiophene nanoparticles using dynamic thermal analysis. Polymer degradation and stability, (2012) 97(1): p. 3-13.

[28.] Shamsipur, M., et al., Biotransformation of methyl tert-butyl ether by human cytochrome P450 2A6. Biodegradation, (2012) 23(2): p 311-318.

[29.] Mehdi Kargarfard, R.R., Ayeh Rizvandi, Mehdi Dahghani, Parinaz Poursafa, Hemodynamic physiological response to acute exposure to air pollution in young adults according to the fitness level. ARYA Atherosclerosis, (2009) 5(3).

[30.] Rizvandi, A., et al., The Evaluation of Performance Indicators of Coaches in Football Development. Journal of Humanities Insights, (2019) 03(04): p. 248-254.

[31.] Aye Rizvandi, M.T.G., Mohammadreza Esmaeili, Farideh Ashraf Ganjoee, The Evaluation of Performance Indicators of Coaches in Football Development. Journal of Humanities Insights, (2019) 3(4).

[32.] Aye Rizvandi, F.T., Zahea Sadegh Zadeh, Sport consumer behaviour model: Motivators and constraints. Universidad de Alicante. Área de Educación Física y Deporte, (2019)14.

[33.] Aye Rizvandi, F.T., Entrepreneurial marketing effects on sport club manager performance (Conceptual Model). Universidad de Alicante. Área de Educación Física y Deporte, (2019). 14.

[34.] Aye Rizvandi, M.F., Maryam Asadollahi Supply Chain Management for Sporting Goods Retailing. 2020: Mikima Book Publication.

[35.] S. Mojtaba Mostafavi, A.R. and A.A. Miranbeigi, Handbook of Mineral Analysis. 2012, Mani Publication, Ltd, Isfahan, Iran.
[36.] Parvanian, S., S.M. Mostafavi, and M. Aghashiri, Multifunctional Nanoparticle Developments in Cancer Diagnosis and Treatmen. Sensing and Bio-Sensing Research, (2016) 1(2): p. 22.

[37.] Mostafavi, S.M. Enhancement of mechanical performance of polymer nanocomposites using ZnO nanoparticles. in 5th International Conference on Composites: Characterization, Fabrication and Application (CCFA-5). Iran University of Science and Technology. (2016)

[38.] Abolfazl Davoudiroknabadi, S.M.M., Seyed Sajad Sajadikhah, An Introduction to Nanotechnology, Mikima Book. (2016)

[39.] Abolfazl Davodiroknabadi, S.M.M., Ali Asghar Pasban, Fundamentals of Nanostructure and Nanomaterial. Mikima Book. (2016)

[40.] Narmin Najafzadeh, M.M.S., Syed Shuja Sultan, Adel Spotin, Alireza Zamani, Roozbeh Taslimian, Amir Yaghoubinezhad, Parviz Parvizi, the existence of only one haplotype of Leishmania major in the main and potential reservoir hosts of zoonotic cutaneous leishmaniasis using different molecular markers in a focal area in Iran. Revista da Sociedade Brasileira de Medicina Tropical, (2014) 47(5).

[41.] Adel Spotin, S.R., Parviz Parvizi, Parnazsadat Ghaemmaghami, Ali Haghighi, Aref Amirkhani, Ali Bordbar, Amir Yaghoubinezhad, Different Phenotypic Aspects with No Genotypic Heterogeneity in Leishmania Major Isolates of Suspected Patients in Northern Khuzestan Province. Iranian Journal of Public Health, (2014) 43(2).

[42.] Neda Samei, P.P., Adel Spotin, Mohammad Reza Khatami Nezhad, Narmin Najafzadeh, Amir Yaghoubinezhad, identifying of causative agents of cutaneous leishmaniases by amplifying cyt b gene in indigenous foci of Iran. Iranian Journal of Public Health, (2014) 43(2).

[43.] Neda Samei, P.P., Mohammadreza Khatami Nezhad, Amir Yaghoubinezhad, Narmin Najafzadeh, Adel Spotin, Finding various molecular haplotypes of Leishmania major in human using three HSp70, ITS-rDNA and Cyt b genes, in 1st and 13th Iranian Genetics Congress. (2014)

[44.] Somayyeh Heidary, A.Y.N., Atefeh Mehrabi Far, Colonization and Investigation of Vibrio Cholera Recombination Protein in E-Coli. International Journal of Engineering \& Technology, (2018) 7(4.7).

[45.] Nezhad, A.Y., et al., Investigation of Shigella lipopolysaccharides effects on immunity stimulation of host cells. International Transaction Journal of Engineering. Management, Applied Sciences and Technologies, (2019) 10: p. 465.

[46.] Hassan, K., The Management of Solid Waste and its Challenges in the India. Journal of Humanities Insights, (2020) 04(01): p. 16-26.

[47.] Zahed, N. and O. Al Rafat, Technical Review of National Accounting Software. Journal of Humanities Insights, (2020) 04(01): p. 11-15.

[48.] Rafieian, S. and M. Esmaeilimotlagh, The investigation of Psychological Position of Elementary School Teachers on their Teaching Performance. Journal of Humanities Insights, (2020) 04(01): p. 6-10.

[49.] Saeedi, A., The Investigation of the Relation of Mental Wellbeing and Sport Activities in Young Students. Journal of Humanities Insights, (2020) 04(01): p. 1-5.

[50.] Batumi, A., The Changes of Irisin Levels in Athletes after Eight Weeks Intensity Internal Training. Journal of Humanities Insights, (2020) 04(01): p. 41-44.

[51.] Ahmadimoghaddam, S., The Application of Internet of Things in Goods Distribution and Supply Chain. Journal of Humanities Insights, (2020) 04(01): p. 32-40.

[52.] Etedalian, H., Application of Packet Arrival Rate for Prediction of Queue Management. Journal of Humanities Insights, (2020) 04(01): p. 29-31.

[53.] Laube, A., Analysis of Risk Measurement in Financial Companies. Journal of Humanities Insights, (2020) 04(01): p. 27-28.

[54.] Pasban, A., et al., Quantitative Determination of LPG Hydrocarbons by Modified Packed Column Adsorbent of Gas Chromatography Via Full Factorial Design. Journal of Nanoanalysis, (2017) 4(1): p. 31-40.

[55.] Somayyeh Heidari, M.I., Seyed Mojtaba Mostafavi, , A Validated and Rapid HPLC Method for Quantification of Human Serum Albumin in Interferon beta-1a Biopharmaceutical Formulation. MedBioTech Journal, (2017) 1(01): p. 29.

[56.] Mostafavi, S.M., K. Bagherzadeh, and M. Amanlou, A new attempt to introduce efficient inhibitors for Caspas-9 according to structure-based Pharmacophore Screening strategy and Molecular Dynamics Simulations. Medbiotech Journal, (2017) 01(01): p. 1-8. 
[57.] Amanlou, M. and S.M. Mostafavi, In sillico screening to aim computational efficient inhibitors of caspase- 9 by ligand-based pharmacophore modeling. Medbiotech Journal, (2017) 01(01): p. 34-41.

[58.] Mostafavi, S.M., et al., Acidity removal of Iranian heavy crude oils by nanofluid demulsifier: An experimental investigation. Journal of Nanoanalysis, (2017) p. 10-17.

[59.] Aida Badamchi Shabestari, B.A.A., Maryam Shekarchi, Seyed Mojtaba Mostafavi, Development of Environmental Analysis for Determination of Total Mercury in Fish Oil Pearls by Microwave Closed Vessels Digestion Coupled with ICP-OES. Ekoloji, (2018) 27(106): p. 1935.

[60.] Samira Eissazadeh, M.P., Mohammad Sadegh Taskhiri and S.M. Mostafavi, Improvement of Sensitivity of Antigen-Antibody Detection of Semen Through Gold Nanoparticle. Research Journal of Pharmaceutical, Biological and Chemical Sciences, (2019) 10(1) p. 144.

[61.] Samira Eissazadeh, M.P. and S.M. Mostafavi, Measurement of Some Amino Acid Using Biosensors Based on Silicon-Based Carbon Nanotubes. Journal of Computational and Theoretical Nanoscience, (2019) 16: p. 1.

[62.] Aida Badamchi Shabestari, S.M.M., Hanieh Malekzadeh, Force Degradation Comparative Study on Biosimilar Adalimumab and Humira. Revista Latinoamericana de Hipertensión, (2019) 13(06): p. 496-509.

[63.] Seyed Mojtaba Mostafavi1, H.M. and M.S. Taskhiri, In Silico Prediction of Gas Chromatographic Retention Time of Some Organic Compounds on the Modified Carbon Nanotube Capillary Column. Journal of Computational and Theoretical Nanoscience, (2019) 16(01): p. 151-156.

[64.] Samira Eissazadeh, S.M.M., Masoumeh Piryaei, and M.S. Taskhiri, Application of Polyaniline Nanostructure Based Biosensor For Glucose And Cholesterol Detection. Research Journal of Pharmaceutical, Biological and Chemical Sciences, (2019) 10(1): p. 150.

[65.] Mostafavi, S.M., S. Eissazadeh, and M. Piryaei, Comparison of Polymer and Ceramic Membrane in the Separation of Proteins in Aqueous Solution Through Liquid Chromatography. Journal of Computational and Theoretical Nanoscience, (2019) 16(1): p. 157164.

[66.] Ahmadipour, A., P. Shaibani, and S.A. Mostafavi, Assessment of empirical methods for estimating potential evapotranspiration in Zabol Synoptic Station by REF-ET model. Medbiotech Journal, (2019) 03(01): p. 1-4.

[67.] Jafari, S. and S.A. Mostafavi, Investigation of nitrogen contamination of important subterranean water in the plain. Medbiotech Journal, (2019) 03(01): p. 10-12.

[68.] Mostafavi, S.M. and A. Ebrahimi, Mercury determination in work place air and human biological samples based on dispersive liquid-liquid micro-extraction coupled with cold vapor atomic absorption spectrometry. Analytical Methods in Environmental Chemistry Journal, (2019) 2(04): p. 49-58.

[69.] Z. Man, A.G.E., S. M. Mostafavi, and A. Surendar, Fuel oil characteristics and applications: economic and technological aspects. Petroleum Science and Technology, (2019)

\section{How to Cite This Article}

Hassan, A., Rabbani, S., and Morni, A., Jafar, H. A. Hydrophobic Interaction Chromatography and Modeling of Protein Adsorption on Hydrophobic Gel, Brilliant Engineering, 1(2021), 1-5. https://doi.org/10.36937/ben.2021.001.001 